\title{
Angiotensin and baroreflex control of the circulation
}

\section{G.A. Head ${ }^{1}$, T. Saigusa ${ }^{2}$ and D.N. Mayorov ${ }^{1}$}

\author{
${ }^{1}$ Neuropharmacology Laboratory, Baker Medical Research Institute, M elbourne, \\ Australia \\ 2Department of Physiology, Yamanashi Medical University, Tamaho, Yamanashi, Japan
}

\author{
Correspondence \\ G.A. Head \\ Baker Medical Research Institute \\ P.O. Box 6492 \\ St. Kilda Rd. Central \\ Melbourne, 8008 \\ Australia \\ Fax: +61-3-8532-1362 \\ E-mail: Geoff.Head@ baker.edu.au \\ Presented at the IV International \\ Symposium on Vasoactive Peptides, \\ Belo Horizonte, M G, Brazil, \\ October 19-21, 2001. \\ Research supported by an \\ Institute grant from the National \\ Health and Medical Research Council \\ of Australia
}

Received December 6, 2001 Accepted January 22, 2002

\section{Abstract}

There is a close association between the location of angiotensin (Ang) receptors and many important brain nuclei involved in the regulation of the cardiovascular system. The present review encompasses the physiological role of Ang II in the brainstem, particularly in relation to its influence on baroreflex control of the heart and kidney. Activation of $\mathrm{AT}_{1}$ receptors in the brainstem by fourth ventricle $(4 \mathrm{~V})$ administration to conscious rabbits or local administration of Ang II into the rostral ventrolateral medulla (RVLM) of anesthetized rabbits acutely increases renal sympathetic nerve activity (RSNA) and RSNA baroreflex responses. Administration of the Ang antagonist Sarile into the RVLM of anesthetized rabbits blocked the effects of Ang II on the RSNA baroreflex, indicating that the RVLM is the major site of sympathoexcitatory action of Ang II given into the cerebrospinal fluid surrounding the brainstem. However, in conscious animals, blockade of endogenous Ang receptors in the brainstem by the $4 \mathrm{~V} \mathrm{AT}_{1}$ receptor antagonist losartan resulted in sympathoexcitation, suggesting an overall greater activity of endogenous Ang II within the sympathoinhibitory pathways. However, the RSNA response to airjet stress in conscious rabbits was markedly attenuated. While we found no effect of acute central Ang on heart rate baroreflexes, chronic $4 \mathrm{~V}$ infusion inhibited the baroreflex and chronic losartan increased baroreflex gain. Thus, brainstem Ang II acutely alters sympathetic responses to specific afferent inputs thus forming part of a potentially important mechanism for the integration of autonomic response patterns. The sympathoexcitatory $\mathrm{AT}_{1}$ receptors appear to be activated during stress, surgery and anesthesia.

\section{Introduction}

It is now becoming well recognized that angiotensin (Ang) not only plays a key role in the regulation of the cardiovascular system within the kidney and vasculature, but also in the central nervous system $(1,2)$. There is a very close association between the location of Ang II receptors and many important brain nuclei involved in cardiovascular regu- lation $(3,4)$. Much interest has been focused on the actions of Ang in the forebrain circumventricular regions such as the subfornical organ and organum vasculosum laminae terminalis which regulate thirst, body fluid and blood pressure $(1,5)$, as well as in the area postrema (6). These regions do not have a blood-brain barrier and can respond to circulating levels of Ang II, thus providing an important link from the kidney to the brain. 
More recently, brainstem vasomotor nuclei such as the nucleus tractus solitarius (NTS), rostral ventrolateral medulla (RVLM) and caudal ventrolateral medulla (CVLM), which all contain high concentrations of Ang type $1\left(\mathrm{AT}_{1}\right)$ receptors, also drew attention as possibly important sites of action of Ang $(7,8)$. While these regions are key integrative centers for central cardiovascular control, they possess a blood-brain barrier which normally prevents any direct contact from circulating Ang. Presumably, Ang receptors in these nuclei are activated by an endogenous Ang system involving either Ang II or Ang III as neurotransmitters or neuromodulators (1).

These nuclei form the fundamental neuronal substrate of the arterial baroreflex with excitatory projections from second-order neurons in the NTS to neurons in the CVLM, and inhibitory projections from the CVLM to the sympathoexcitatory neurons in the RVLM. The pattern of $\mathrm{AT}_{1}$ receptor distribution thus suggests that Ang may act at these nuclei exerting both excitatory and inhibitory influence on baroreflex control of cardiovascular function. However, it would be an oversimplification to suggest that Ang exerts mostly an excitatory action in the RVLM and an inhibitory action in the CVLM because of increasing evidence that its actions in the same nuclei may critically depend on the endogenous activity of the Ang system.

The present brief review discusses the role of Ang II in the hindbrain, particularly in relation to its influence on baroreflex control of the heart and kidney. In this review we will not consider the role of Ang in the area postrema on the arterial baroreflex, since it has recently been discussed in detail elsewhere (6).

\section{Cardiovascular effects of intraventricular Ang}

Stimulation of central Ang II receptors has been shown to increase arterial pressure in various species (1). A common approach used to investigate the cardiovascular role of the central Ang system has been to administer Ang peptides into the cerebral ventricles. Bickerton and Buckley (9) demonstrated in the early 1960's that Ang II given into the lateral ventricle could elicit a centrally mediated pressor response in the dog. Studies by Severs and colleagues (10) showed a pressor response from perfusion of the lateral ventricle of anesthetized cats with Ang II. Preventing the perfusate from leaving the lateral and third ventricles blocked the response, suggesting a site of action at or below the midbrain level. Hoffman and Phillips (11) examined the effects of intraventricular administration of Ang II to conscious rats and found marked pressor and dipsogenic responses via the lateral ventricle as well as the anterior and posterior third ventricle. In this species, however, the site of action involved the anterior ventral third ventricle which correlates well with the location of the receptors and is relatively close to the injection site. In conscious rabbits, however, lateral or third ventricle injections of Ang II had little effect on blood pressure with doses as large as $1000 \mathrm{pmol}$ (Figure 1) (12). The rabbit also does not respond to chronic infusions of Ang into the lateral ventricle (13) nor does acute injection of Ang produce dipsogenic responses (14) as it does in the rat.

Unlike the forebrain, the role of an Ang system in the brainstem has received relatively little attention until recently. Early studies showed that injecting Ang II into the fourth ventricle $(4 \mathrm{~V})$ of rats produced no change in blood pressure, suggesting that this region was not a major site of action for Ang (11) despite high concentrations of Ang receptors in hindbrain areas such as the NTS and area postrema. By contrast, we found that conscious rabbits are most sensitive to Ang II given into the $4 \mathrm{~V}(15,16)$. Bolus injections of Ang II produced dose-dependent increases in blood pressure with doses 
about 400 times lower than those given intravenously (Figure 1). The onset of the response was relatively quick, within $1 \mathrm{~min}$, and generally lasted only $5 \mathrm{~min}$, depending on the dose (12). The receptors were $\mathrm{AT}_{1}$ since the pressor response to Ang II administered into the $4 \mathrm{~V}$ of conscious rabbits was completely blocked by low doses of the nonpeptide selective antagonist losartan but not affected by the $\mathrm{AT}_{2}$ antagonist PD123319 (17).

The importance of the sympathetic nervous system in mediating central cardiovascular effects of Ang has been recognized since the mid 1960's in all species studied although relatively few studies have measured nerve activity directly (18). A number of studies suggest that in the rat there is an important contribution to the pressor response by release of vasopressin (19). However, direct recordings of renal sympathetic nerve activity (RSNA) do show a significant increase in RSNA concomitant with the pressor response following Ang II injected into the third ventricle in rats (20). Tobey and colleagues (21) observed a marked increase in splanchnic nerve activity but no effect on RSNA following intraventricular administration of Ang II using anesthetized, sinoaortic denervated and vagotomized cats, suggesting there may be differential effects on sympathetic activity depending on the vascular bed.

In contrast to the rat, the pressor response observed with $4 \mathrm{~V}$ Ang II given to conscious rabbits is predominantly due to sympathetic vasoconstriction since it is blocked by intravenous prazosin (16). The vasoconstriction occurred in both the mesenteric and renal vascular beds but was accompanied by dilatation of the hindlimb vascular bed and a fall in heart rate which opposed the vasoconstriction and reduced the observed pressor response. However, the hindlimb dilatation changed to vasoconstriction in rabbits after sinoaortic denervation, suggesting that it was mainly due to a baroreflex response to the rise in blood pressure (12).

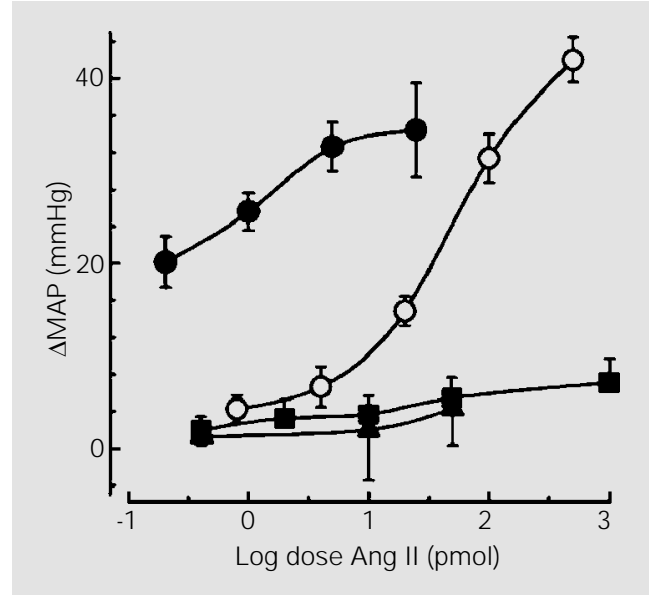

Figure 1. Average dose-response relationships from conscious rabbits given Ang II into the fourth ventricle (filled circles, $\mathrm{N}=7$ ), lateral ventricle (squares, $N=9$ ), third ventricle (triangles, $\mathrm{N}=5$ ) and intravenously (open circles, $\mathrm{N}=8$ ). Vertical bars are means \pm SEM and indicate between-animal variance. MAP $=$ Mean arterial pressure. Data from Head and Williams (12) with permission.

\section{Effects of baroreceptor denervation on the action of central Ang}

The profound increase in the sensitivity to central Ang II after sinoaortic denervation has been observed in rats with lateral ventricle administration (22). The increase was $\sim 300$ times greater than would be expected from loss of peripheral baroreflex function and was due to similar increases in sympathetic outflow and vasopressin-mediated vasoconstriction. In the conscious rabbit, chronic sinoaortic denervation augmented the sensitivity to Ang II given into the $4 \mathrm{~V}$ by 900 -fold. This effect was not observed in animals with depletion of spinal noradrenergic pathways, indicating that sensitization of the brainstem noradrenergic neurons to Ang may play a key role in this phenomenon (16). This also suggests that pressor responses to central Ang II are normally suppressed by profound baroreflex inhibition. Furthermore, the Ang receptors that have been stimulated by $4 \mathrm{~V}$ administration may be of greater physiological importance when the baroreflex is not functioning effectively as is the case in hypertension and heart failure $(23,24)$.

\section{Effects of fourth ventricle Ang II on cardiac and sympathetic baroreflexes}

While much has been written about the 
effect of circulating Ang on cardiac and sympathetic baroreflexes, very few studies have examined the effect of intraventricular Ang on baroreflexes. In conscious rabbits Dorward and Rudd (25) found that 4V Ang II produced a marked increase in RSNA when the baroreceptors were unloaded with decreasing blood pressure. Thus, the upper plateau of the RSNA baroreflex curve was doubled and the curve shifted to the right due to the increase in blood pressure. We observed a similar pattern of effect of $4 \mathrm{~V}$ Ang II on the RSNA baroreflex in urethane-anesthetized rabbits (Figure 2) (26). Recently, we also infused Ang II into the lateral recess of the $4 \mathrm{~V}$ in conscious rabbits (27). Although in our study Ang infusion evoked pressor responses similar to those observed by Dorward and Rudd (25), the magnitude of the RSNA increase after the baroreceptor unloading was lower (Figure 2). This difference may indicate that access to the dorsal medulla and area postrema, which were much closer to the infusion site in the former study, may be critical in the excitatory action of intraventricular Ang II on the RSNA baroreflex in conscious rabbits.
Infusion of Ang II (2.5-25 pmol/min) into the third (28) or fourth (25) ventricle acutely reset baroreflex control of heart rate to a higher pressure but did not affect the sensitivity or range of this reflex in conscious rabbits. Importantly, in both studies intravenous infusion of the same dose of Ang II had no effect on the baroreflex. More recently, we also found similar effects of infusion of a low dose of Ang II into the lateral recess of the $4 \mathrm{~V}$ on cardiac baroreflex in rabbits (Figure 3) (27). It is interesting to note that the resetting appears to be complete. However, since this occurs within 20 min, this is highly unlikely from what is known about the time course of baroreceptor resetting (29). One possible explanation for the lack of acute bradycardia may be the fact that Ang II is also exciting cardiac sympathetic pathways in the brainstem. The advantage of such a combination of actions is that Ang can modulate the level of blood pressure rapidly while maintaining the very shortterm regulation of heart rate within the high gain area of the reflex curve.

Studies concerning the cardiovascular role of central Ang II have predominantly
Figure 2. Average mean arterial pressure (MAP) and renal sympathetic nerve activity (RSNA) baroreflex curves before (control, dotted lines) and during infusion of Ang II into the fourth ventricle (solid line) from 6 urethane-anesthetized rabbits (left panel) and 5 conscious rabbits (right panel). Circles on curves are basal values. $\mathrm{nu}=$ normalized units. $* \mathrm{P}<0.05$ for difference between upper plateaus. Adapted with permission from Refs. 26,27.

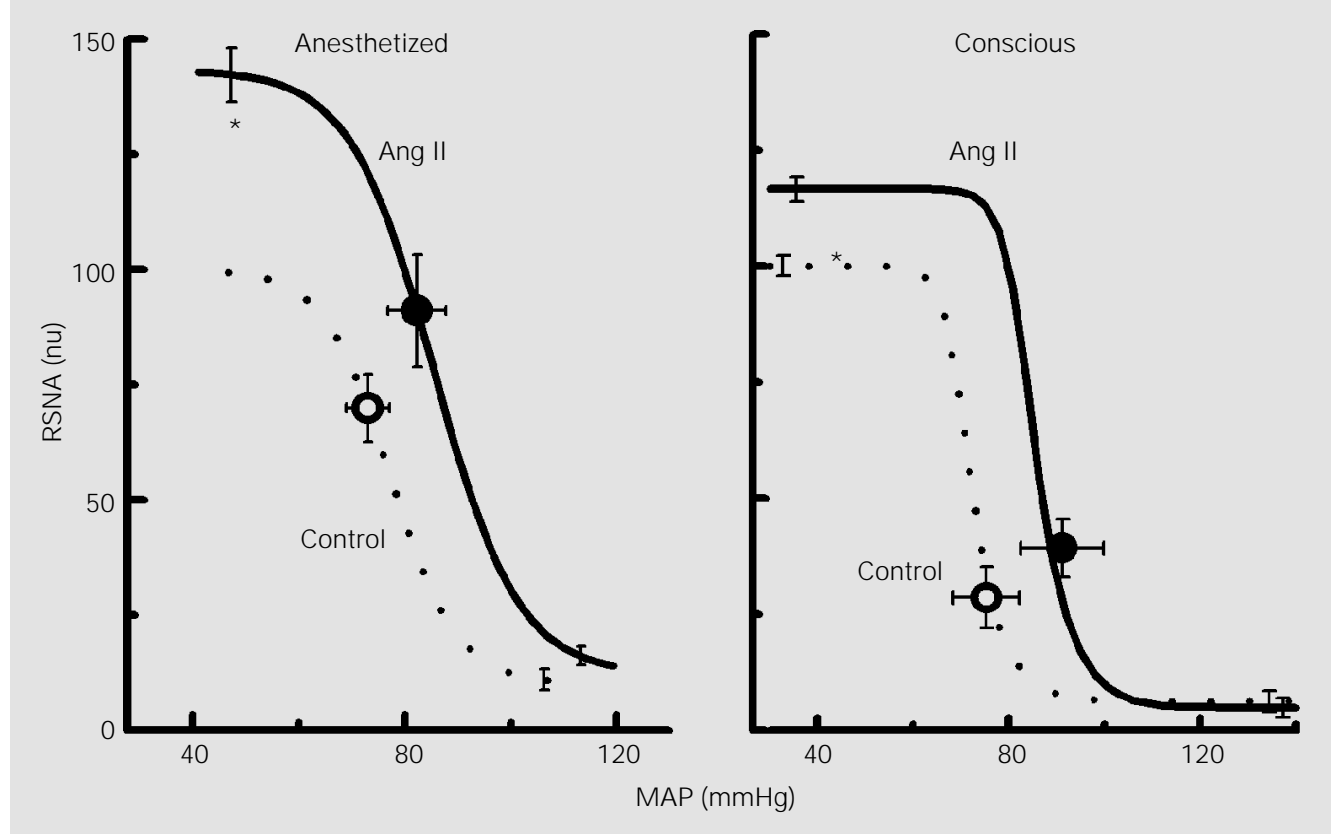


involved acute administration of agonists and antagonists. However, perhaps even more important for the cardiovascular system is the impact of chronic activation or inhibition of central Ang II receptors. It has been known since the earlier 1980's that central infusion of Ang produces hypertension and central inhibition of the renin-angiotensin system attenuates hypertension (30). Despite many such subsequent studies, relatively few have examined cardiovascular reflex mechanisms. We recently examined the effect of chronic activation of central Ang II receptors on cardiac baroreflex function in conscious normotensive rabbits. Animals received a $4 \mathrm{~V}$ infusion by osmotic minipump of Ang II for 2 weeks. Assessment of the heart rate baroreflex was performed by a single slow ramp rise and fall in blood pressure by intravenous infusion of phenylephrine and by caval balloon inflation, respectively. Ang II (100 ng/ h) decreased cardiac baroreflex gain by $-20 \%$ after 1 week and by $-37 \%$ after 2 weeks (Figure 3) (31). The intriguing feature of this study was that the effect of Ang II took the full 2 weeks to develop. Within a week of stopping the infusion, cardiac baroreflex gain had returned to control levels (Figure 3). Ringer's solution or lower doses of Ang II did not modify the cardiac baroreflex function. Blood pressure and heart rate were not altered by any treatment nor was their vari- ability affected as assessed by power spectral analysis (31).

\section{Effects of endogenous Ang in the hindbrain on baroreflexes}

There has been a great deal of interest in the cardiovascular role of the endogenous Ang system within the brain. The most effective method to determine the tonic activity of an endogenous Ang system has been to apply a specific receptor antagonist of converting enzyme inhibitor. Dorward and Rudd (25) examined the renal sympathetic and heart rate baroreflex effects of the specific, but non-subtype selective Ang II antagonist [Sar ${ }^{1}, I^{8}{ }^{8}$ ]-Ang II (Sarile) into the $4 \mathrm{~V}$ of conscious rabbits. The antagonist had no effect on renal sympathetic reflexes whilst an Ang-converting enzyme inhibitor, enalaprilat, slightly enhanced maximal baroreflex sympathetic responses. By contrast, in a similar conscious rabbit preparation, we found that the specific $\mathrm{AT}_{1}$ receptor antagonist losartan increased resting RSNA and the upper plateau of the RSNA baroreflex, while blood pressure remained unaltered (Figure 4) (17). These results were somewhat surprising given that the receptor antagonist produced effects qualitatively similar to those of Ang itself and suggested that losartan is blocking a tonically active sympathoinhibitory action
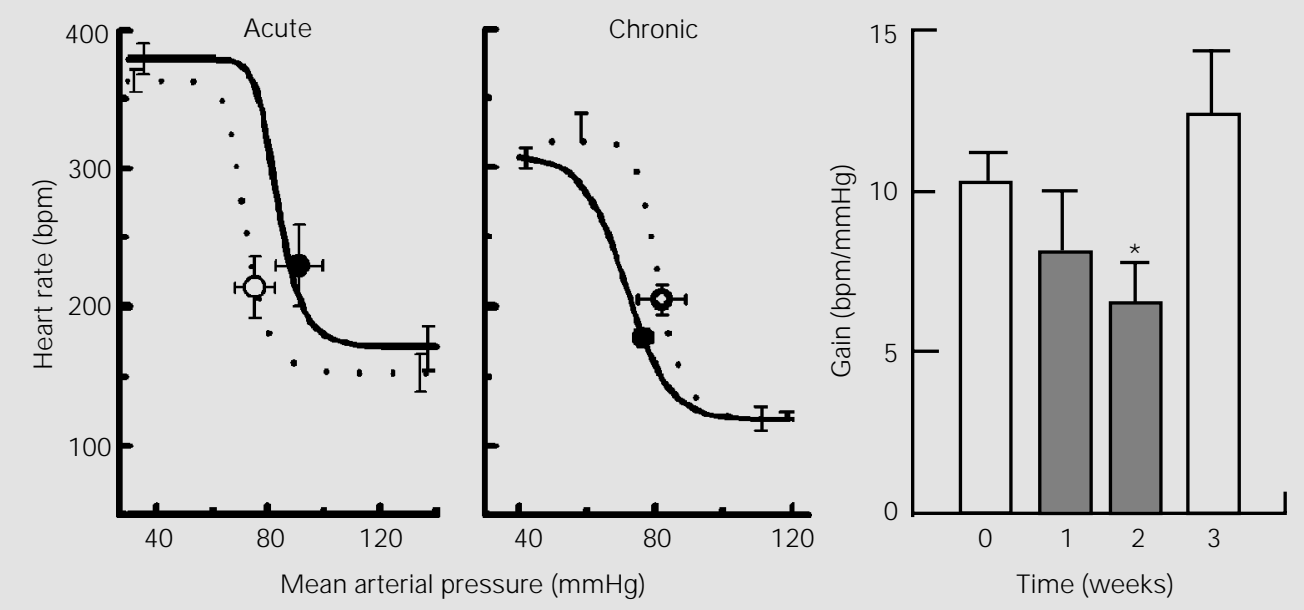

Figure 3. Cardiac baroreflex curves before and after acute $(4$ $\mathrm{pmol} / \mathrm{min})$ or chronic $(100 \mathrm{ng} / \mathrm{h}$ for 2 weeks) fourth ventricle (4V) infusion of Ang II in conscious rabbits (left and middle panels). Dotted line - control, black line - Ang II. Right panel, Gain of the cardiac baroreflex before (week 0 , left open bar), during (weeks 1 and 2, gray bars) and after (week 3, right open bar) 2-week $4 \mathrm{~V}$ infusion of Ang II $(100 \mathrm{ng} / \mathrm{h}) . * \mathrm{P}<0.05$ for comparison between control and treatment. Error bars are average SEM. Figures adapted with permission from Refs. 27,31 . 
of endogenous Ang (compare Figures 3 and 4). However, the effects of trigeminal stimulation were not affected by losartan, suggesting that Ang normally modulates specific inputs to the presympathetic neurons, possibly by a presynaptic action. The action of losartan was most likely a specific effect since in a later study we observed similar changes with the Ang-converting enzyme inhibitor, enalapril (32), indicating a primary inhibitory role of hindbrain $\mathrm{AT}_{1}$ receptors in conscious normotensive rabbits. Whilst at this stage we do not know the site of action of the sympathoinhibitory Ang pathways, possibilities include the CVLM and the NTS (see below).

In all the above studies in intact rabbits, acute administration of various Ang II receptor antagonists neither changed resting blood pressure or heart rate, nor affected cardiac baroreflexes $(17,25,32)$. However, rabbits with pacing-induced heart failure have inhibition of cardiac baroreflex function which can be restored by the $\mathrm{AT}_{1}$ receptor antagonist L-158,509 (33). By contrast, the cardiac baroreflex sensitivity in non-paced rabbits was not altered by $\mathrm{AT}_{1}$ receptor blockade. Thus, the participation of central Ang II in inhibiting cardiac baroreflexes does not appear to occur in the normal animal but re-

Figure 4. Average renal sympathetic nerve activity (RSNA) baroreflex curves before and after injection of losartan $(10 \mu \mathrm{g})$ into the fourth ventricle $(4 \mathrm{~V})$ in conscious rabbits (left panel). Middle panel, Cardiac baroreflex curves before and after chronic $(30 \mu \mathrm{g} / \mathrm{h}$ for 2 weeks) $4 \mathrm{~V}$ infusion of losartan. Dotted line - control, black line - losartan. Right panel, Gain of the cardiac baroreflex before (week 0, left open bar), during (weeks 1 and 2, gray bars) and after (week 3, right open bar) 2week $4 \mathrm{~V}$ infusion of losartan (30 $\mu \mathrm{g} / \mathrm{h}) . * \mathrm{P}<0.05$ for comparison between control and treatment. Error bars are average SEM. nu $=$ normalized units. Adapted with permission from Refs. 17,31 . diovascular system such as heart failure.
We recently examined the effect of chronic inhibition of central Ang II receptors on cardiac baroreflex function in conscious normotensive rabbits. Animals received a $4 \mathrm{~V}$ infusion by osmotic minipump of losartan for 2 weeks. Losartan $(30 \mu \mathrm{g} / \mathrm{h})$ increased baroreflex gain by $+24 \%$ and $+58 \%$ after 1 and 2 weeks, respectively (Figure 4), but did not change resting blood pressure or heart rate (31). Similarly, chronic but not acute administration of the $\mathrm{AT}_{1}$ receptor antagonist EXP 3174 has been shown to normalize cardiac baroreflex function in SHR (34). These data indicate that there is a long-term modulation of cardiac baroreflexes by endogenous Ang II which is independent of the blood pressure level. The reason for such a long time course is not clear since activation of neuronal $\mathrm{AT}_{1}$ receptors by Ang II occurs relatively rapidly, being due to a reduction in $\mathrm{K}^{+}$current via protein kinase $\mathrm{C}$ and raised intracellular $\mathrm{Ca}^{2+}$ and stimulation of $\mathrm{Ca}^{2+}$ current. Possibly there is long-term regulation of the receptor or altered expression of $\mathrm{AT}_{1}$ receptors. Another possibility may involve an interaction with nitric oxide. Zucker and colleagues (35) have elegantly shown an important interaction between nitric oxide and Ang in the modulation of baroreflexes in heart failure. They suggest that the acute inhibitory effect of Ang on the baroreflex gain is opposed by the facilitatory effect of

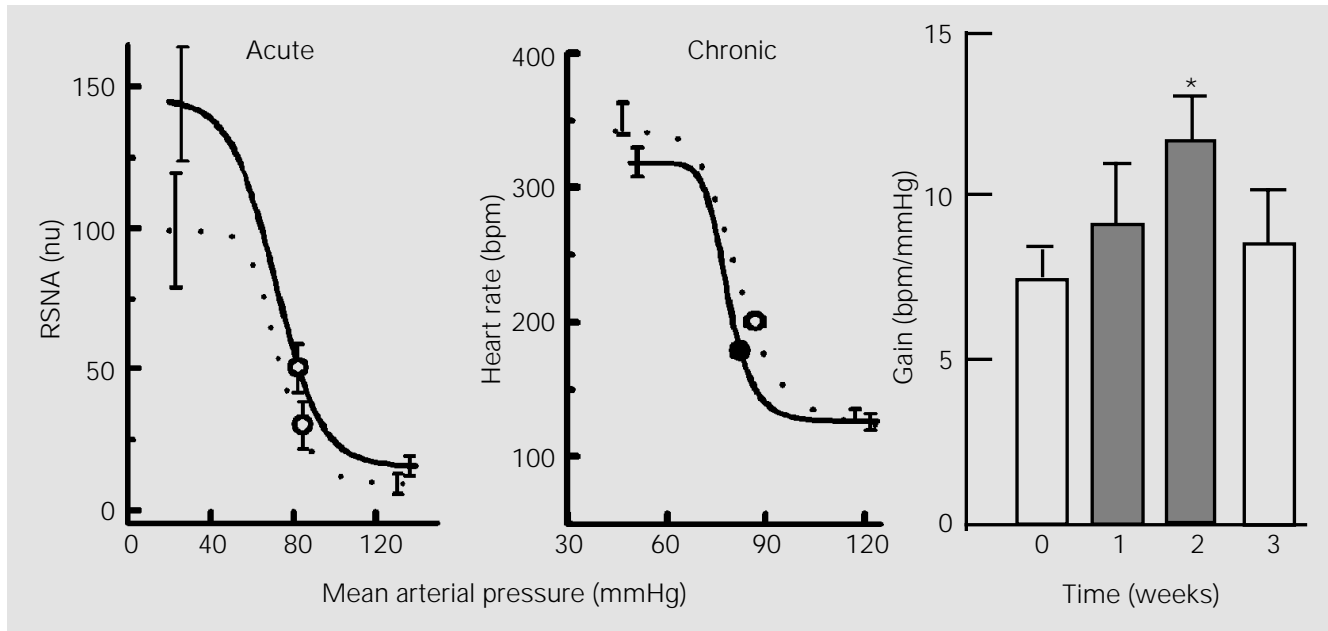


nitric oxide, but chronically, as is the case with heart failure, a reduction in nitric oxide synthase amplifies the effects of Ang II.

\section{Brainstem sites of action of fourth ventricle Ang II}

Intraventricular administration has been a useful tool particularly in conscious animals to help unravel the role of the Ang peptides within the central nervous system but is limited by agents given in this way influencing large brain regions rather than specific nuclei. In order to determine the distribution of neurons within the medulla activated by infusion of Ang II into the $4 \mathrm{~V}$ of conscious rabbits, we used the expression of Fos, the protein product of the immediate early gene c-fos, as a marker of neuronal activation in baroreceptor intact and barodenervated animals (36). Ang II induced a marked increase in the number of Fospositive neurons in the NTS and in the rostral, intermediate, and caudal parts of the ventrolateral medulla with $30-75 \%$ of cells being double-labeled for Fos- and tyrosine hydroxylase immunoreactivity (36) (Figure 5). We found that the distribution of Fospositive neurons closely correlated with the location of Ang II receptor-binding sites as previously determined in the rabbit.

\section{Actions of Ang II in the rostral ventrolateral medulla on baroreflexes}

Of the regions that we examined using the Fos technique, it is clear that perhaps the most important is the RVLM where Ang peptides are likely to have their major sympathoexcitatory action (7). The RVLM is a major source of excitatory drive to the preganglionic sympathetic neurons in the spinal cord and contains high Ang II receptor binding in the rabbit (4) and other species including the cat and dog (37). The existence of Ang II immunoreactive fibers in the ventro- lateral medulla and extended neural processes of the RVLM neurons close to the ventral surface (38) suggest that Ang II may have ready access to the RVLM neurons both from neural pathways and from cerebrospinal fluid. Allen and co-workers (39) demonstrated that direct microinjection of Ang II into the subretrofacial pressor region in the RVLM of the cat resulted in a pressor response. Andreatta and colleagues (40) suggested that the RVLM may contain a reninangiotensin system since Ang I applied to the ventral surface of the brainstem of the cat produced an increase in blood pressure after conversion to Ang II. Sasaki and Dampney (41) found that the sites which produced the greatest increase in blood pressure in the RVLM were also the sites containing the highest concentration of Ang receptors. We initially mapped various dorsal and ventral sites with microinjections of Ang II and found that marked pressor responses were observed only when Ang II was administered into a discrete region of the RVLM corresponding to the subretrofacial nucleus. We found that injections as close as $1 \mathrm{~mm}$ from this region gave very much smaller pressor responses, suggesting that the Ang II-sensitive site is relatively small. Doseresponse curves to Ang II in this region indicated that very low doses were required, with the half maximal dose being approximately 9 fmol. This was approximately 100fold less than that required by the $4 \mathrm{~V}$ route and consistent with the earlier findings of Sasaki and Dampney (41) and others using cats $(39,40)$.

We also observed that local microinfusion of Ang II into the RVLM produced facilita-

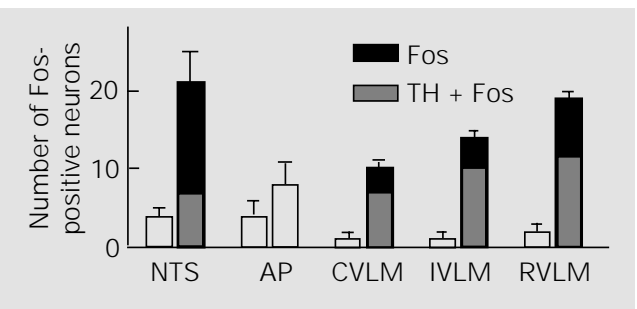

Figure 5. Number of Fos-positive neurons per section in different hindbrain regions after fourth ventricle administration of Ang II (4-8 pmol/min, filled bars) or Ringer's solution (open bars) in conscious sinoaortically denervated rabbits. The number of tyrosine hydroxylase (TH) containing Fos-positive cells are shown in gray bars. NTS = nucleus tractus solitarius ; $\mathrm{AP}=$ area postrema; CVLM = caudal ventrolateral medulla; IVLM = intermediate ventrolateral medulla; RVLM = rostral ventrolateral medulla. Data adapted with permission from Hirooka et al. (36). 
tion of the renal sympathetic baroreflex (Figure 5) which was closely similar to that produced by $4 \mathrm{~V}$ administration (Figure 2) (26). We found that glutamate infusions into the same region of the RVLM had effects similar to those of Ang, increasing blood pressure, resting RSNA and the upper sympathetic baroreflex plateau without affecting the lower plateau (Figure 6) (26). The similarity of Ang actions to those of glutamate suggests that it may directly excite sympathetic vasomotor cells in this region. Indeed, electrophysiological studies have shown that Ang appears to directly excite bulbospinal $\mathrm{C} 1$ neurons (42) by activating postsynaptic $\mathrm{AT}_{1}$ receptors, resulting in a depolarization involving the closing of $\mathrm{K}^{+}$channels (43).

Microinjection techniques into the RVLM have been widely used to limit drug action to small brain regions, but until recently, have been confined in most cases to anesthetized preparations since this area is close to the flexion point of the cervical spinal cord and is subject to movement in the conscious animal. However, the role of Ang peptides in

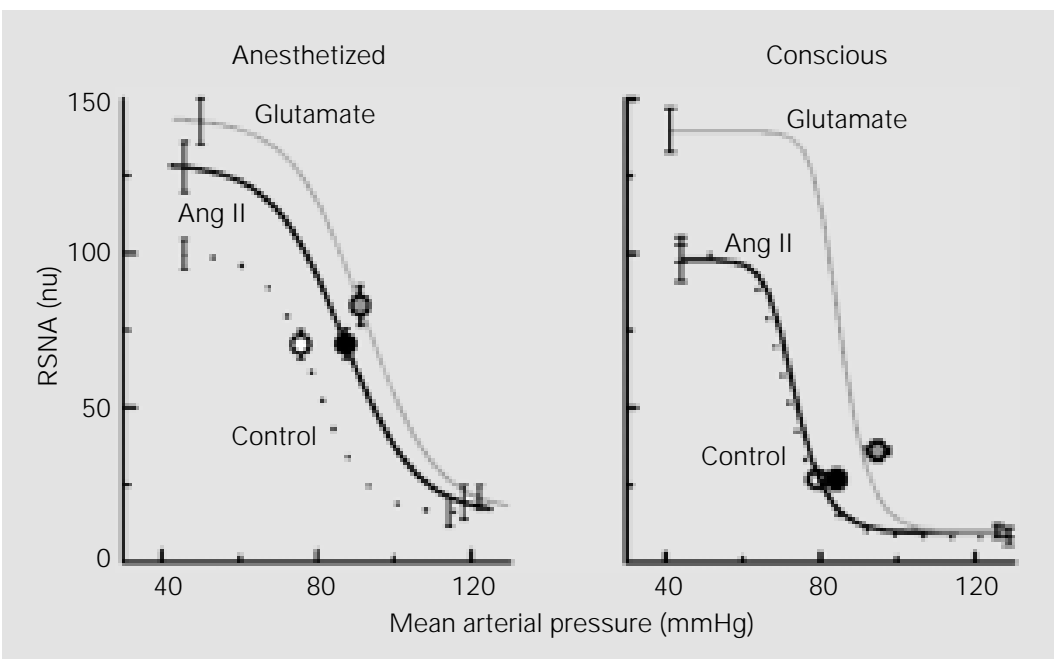

Figure 6. Average mean arterial pressure and renal sympathetic nerve activity (RSNA) curves before (control, dotted lines) and during infusion of Ang II (black lines) or glutamate (gray lines) into the rostral ventrolateral medulla in 6 urethane-anesthetized rabbits (left panel) or in 7 conscious rabbits (right panel). Error bars are average SEM calculated from analysis of variance indicating variation within animals. $\mathrm{nu}=$ normalized units. Adapted with permission from Mayorov and Head (27). the ventrolateral medulla may be very much influenced by the anesthetized animal preparations. Indeed, a high degree of surgical stress is typically associated with microinjection into the RVLM in the acute anesthetized preparation, and hormonal systems such as the renin-angiotensin system have been reported to become activated during anesthesia and surgery (44). Due to their quiet nature, we have found that rabbits are suitable animals for microinjection into the RVLM while conscious and sitting in a standard rabbit box otherwise unrestrained. We therefore developed a new cannula system which permitted us to make repeated bilateral microinjections into the RVLM of conscious rabbits (27). We used this new technique to examine the role of Ang II in the RVLM while measuring RSNA at rest and during baroreflex responses. Bilateral microinjection of Ang II (10 and 20 pmol) into histologically verified pressor regions of the RVLM did not change blood pressure or RSNA. We did observe that a higher Ang II dose of 30 pmol gradually increased blood pressure by $8 \mathrm{mmHg}$, without affecting RSNA. The time course of the increase in MAP was slow, with MAP starting to increase within 0.5 to $1 \mathrm{~min}$ and reaching a peak within 4 min of completion of the injection. Bilateral microinfusion of Ang II (4 $\mathrm{pmol} / \mathrm{min}$ for $20 \mathrm{~min}$ ) did not affect resting MAP or RSNA (27). During the infusion of Ang II baroreflexes were examined but no effects were observed (Figure 6). At the same site glutamate produced increases in blood pressure and renal sympathetic activity and augmentation of the RSNA baroreflex in a similar fashion to what was seen in the anesthetized animal (Figure 6, compare right and left panels). By contrast, infusion of the same dose of Ang II into the $4 \mathrm{~V}$ cerebrospinal fluid increased blood pressure and RSNA by 22 and $34 \%$, respectively (Figure 2), suggesting that sites other than the RVLM may be mediating these responses. 


\section{Cardiovascular effects of blocking endogenous Ang II in the rostral ventrolateral medulla}

Administration of 10 pmol of the antagonist Sarile bilaterally into the subretrofacial region of anesthetized rabbits blocked the pressor response to locally applied Ang II and reduced the pressor responses to $4 \mathrm{~V}$ Ang II by two thirds (Figure 7). This is perhaps the strongest evidence to suggest that the RVLM is the major site of action for Ang II given into the cerebrospinal fluid surrounding the brainstem but the remaining response suggests that other sites make a small contribution.

There has been very much interest in whether there is a contribution to maintaining sympathetic tone by Ang II endogenously released in the RVLM. Andreatta and coworkers (40) provided the first evidence of tonically active Ang II in the RVLM of the anesthetized cat by showing that with the same topical application approach [Sar $\left.{ }^{1}, \mathrm{Thr}^{8}\right]$-Ang II (13 nmol) decreased blood pressure by $8 \mathrm{mmHg}$. However, we did not observe any change in blood pressure or RSNA by giving an effective dose of Sarile (10 pmol) to urethane-anesthetized rabbits. This contrasts the findings of other groups that found a marked reduction in blood pressure with this agent or with $\left[\mathrm{Sar}^{1}, \mathrm{Thr}^{8}\right]$-Ang II $(41,45)$. A recent study suggests, however, that this effect is not related to the blockade of Ang II receptors (46). Presumably this was an effect observed only at much higher doses used in these studies (100-1000 pmol) since we observed no effect on basal blood pressure using 10 pmol, but still had a complete blockade of the pressor response when Ang II was administered into the RVLM. Since we did not observe any attenuation of the glutamate response, the blockage by Sarile was likely to be specific.

We found that bilateral infusion of Sarile (10 pmol + $1 \mathrm{pmol} / \mathrm{min}$ ) into the RVLM did not alter the RSNA baroreflex in urethane- anesthetized rabbits, indicating that there is little influence of endogenous Ang II on the sympathetic baroreflex. Subsequent infusion of Ang II into the $4 \mathrm{~V}(10 \mathrm{pmol} / \mathrm{min})$ had no further effect in the animals pretreated with Sarile (Figure 7). We also determined the effects of blocking Ang receptors in a conscious rabbit preparation (27). Pretreatment with Sarile into the RVLM (100-500 pmol) did not change resting blood pressure, RSNA or renal sympathetic baroreflex parameters. The lack of an effect inhibiting Ang II receptors in the RVLM was unlikely to be due to leakage of the antagonist into the depressor region of the CVLM, since its bilateral microinjections into the intermediate ventrolateral medulla at or just rostral to the obex level also did not alter resting or baroreflex parameters.

The lack of effect inhibiting Ang II receptors in the RVLM is consistent with our previous findings in anesthetized animals but the lack of effect of Ang II itself is somewhat surprising. One possibility is that the action of Ang II may depend very much on the state of excitatory inputs to the region. Fontes and colleagues (47) had also developed a method for administration of agents into the RVLM but in conscious rats. They showed that Ang II and Ang 1-7 increased

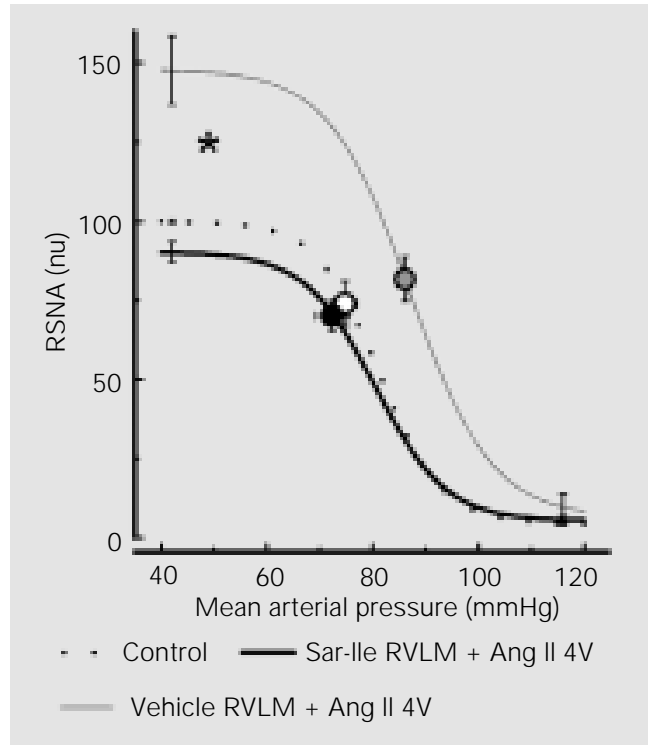

Figure 7. Average mean arterial pressure and renal sympathetic nerve activity (RSNA) baroreflex curves from 4 anesthetized rabbits before (dotted line) and during infusion into the rostral ventrolateral medulla (RVLM) of $\left[\mathrm{Sar}^{1}, \mathrm{Ile}^{8}\right.$ ]-Ang II (10 pmol + 1 $\mathrm{pmol} / \mathrm{min}$, black line) or vehicle (gray line) followed by fourth ventricular (4V) infusion of Ang II (10 pmol/min). Error bars are SEM indicating variation within animals. $* \mathrm{P}<0.05$ for a difference between upper plateaus. nu $=$ normalized units. 
blood pressure while the peptide antagonist Sarile produced a small decrease in blood pressure. They observed an increase in blood pressure with two different $\mathrm{AT}_{1}$ receptor antagonists which may be related to our observations that losartan produced an increase in sympathetic activity when given $4 \mathrm{~V}$ to conscious rabbits (17). One possibility is that the relatively large volume of $200 \mathrm{nl}$ enabled the drug to block the sympathoinhibitory action of Ang in the CVLM. The other possibility is that the effect of Ang II depends on the synaptic inputs to the premotor cells. Electrophysiological studies have shown that Ang II increases input resistance of the vasomotor cell body which should have the effect of potentiating both excitatory and inhibitory synaptic inputs (43). In support of this concept, Fontes and colleagues (47), who showed that the $\mathrm{AT}_{1}$ receptor antagonist CV11974 produced an increase in blood pressure in normotensive rats (blocking a predominant depressor role of Ang peptides), also found that this drug produced a depressor response in the hypertensive transgenic rat harboring the mouse Ren-2 gene (blocking a predominant pressor response). They suggested that the role of Ang peptides depends on the endogenous activity of the Ang system. In support of this we have recently found that blockade of Ang II receptors in the RVLM attenuated the renal sympathoexcitatory responses to airjet stress.

\section{Ang actions within the caudal ventrolateral medulla}

Activation of the CVLM causes sympathoinhibition which is mediated by a short ascending inhibitory projection from the CVLM to the RVLM (48). Electrophysiological studies show that tonically active sympathoinhibitory neurons in the CVLM tonically inhibit the firing of sympathoexcitatory barosensitive neurons in the RVLM of the rabbit (49). While the CVLM of the rabbit contains Ang II receptors (4), there have been relatively few studies investigating the role of Ang receptors in this region. Microinjection of Ang II into the region of the A1 noradrenergic cells within the CVLM of the rabbit results in a depressor response (50). The most extensive study was performed by Saigusa and colleagues (51) who found that Ang II infusion into the CVLM of anesthetized rabbits decreased sympathetic activity and inhibited RSNA baroreflex while blockade of CVLM Ang receptors increased the sympathetic baroreflex but did not alter resting blood pressure or RSNA.

\section{Ang actions within the nucleus tractus solitarius}

Within the medulla, the NTS has been the most extensively studied with respect to a likely site of action of Ang peptides. The NTS is the nucleus containing the primary termination of baroreceptor and chemoreceptor afferents (52) but, more importantly, in most species including humans, cats, rabbits and rats, the NTS contains the highest concentration of Ang receptors within the medulla $(4,53)$. Thus, it is not surprising that this nucleus has been suggested as a main region for Ang influencing baroreceptor afferent information $(8,54)$ as well as the integration of chemoreceptor afferents (54). In anesthetized rats, microinjection of Ang into the NTS produces pressor responses at nmol doses (55) and depressor responses at pmol doses (56), and attenuates the baroreceptor reflex $(57,58)$ through $\mathrm{AT}_{1}$ receptors. Our own studies in anesthetized rabbits are consistent with these findings since we observed mainly depressor responses to 1 pmol Ang II injected into the dorsomedial region. This decrease may involve an increase in GABA release and possibly nitric oxide release (54). Conversely, blockade of the Ang II receptors increases blood pressure or has no effect (59) but appears to consistently increase the gain of the baroreflex $(59,60)$. 


\section{Conclusion}

In recent years we have made clear progress in the understanding of the importance of Ang peptides and receptors within the brainstem to cardiovascular regulation. There is a growing recognition from a variety of different studies that the effects of activating Ang II receptors in the RVLM, CVLM and NTS appear to be very much dependent on the state of the animal and the activity of specific afferent information. This aspect may be a critically important mechanism for the adaptive ability of the central nervous system to respond with appropriate autonomic response patterns depending on the situation. The development of the microinjecting system for conscious animals opens the way to a more complete investigation of the neurotransmitter mechanisms within the RVLM without the constraints of anesthesia and will permit an investigation into the role of Ang peptides in mediating the circulatory responses to emotional and behavioral stimuli. For the most part, in conscious normal animals there is relatively little tonic sympathoexcitatory influence at the level of the RVLM as shown by the observations that blockade of $\mathrm{AT}_{1}$ receptor antagonists does not change blood pressure by very much and in some cases increases it. The latter finding indicates that in conscious animals the sympathoinhibitory influence of Ang is more evident and is less active in anesthetized preparations. This sympathoinhibition appears to be mainly mediated by an interaction with baroreceptor inhibitory inputs to the vasomotor neurons since the sympathoinhibitory actions of Ang II are of greatest influence during hypotension. Studies in rats and rabbits suggest that the excitatory action of Ang II is normally under profound baroreceptor inhibition since the sensitivity to Ang is markedly increased in barodenervated animals and the sympathoexcitatory effect of Ang is most evident when baroreceptor input is reduced. On the other hand, baroreflexes themselves can be modulated by Ang peptides over several weeks of drug administration. The precise mechanism of this longterm action remains to be elucidated. There is now much evidence to show that in situations where there are increased excitatory and decreased inhibitory inputs to the RVLM brainstem, such as barodenervation, acute stress, hypertension or heart failure, the sympathoexcitatory Ang system within the brainstem clearly becomes very important.

\section{Acknowledgments}

The authors wish to acknowledge the contribution of their collaborators Jean-Luc Elghozi, Naomi Williams, Robert Bendle, Elisabeth Lambert, Yoshitaka Hirooka and Roger Dampney to the work described in this review.

\section{References}

1. Phillips MI (1987). Functions of angiotensin in the central nervous system. Annual Review of Physiology, 49: 413-435.

2. Reid IA (1992). Interactions between ANG II, sympathetic nervous system, and baroreceptor reflexes in regulation of blood pressure. American J ournal of Physiology, 262: E763-E778.

3. Mendelsohn FAO, Guirion R, Saavedra J M, Aguilera G \& Catt KJ (1984). Autoradiographic localisation of angiotensin II receptors in rat brain. Proceedings of the
National Academy of Sciences, USA, 81: 1575-1579.

4. Mendelsohn FAO, Allen AM, Clevers J, Denton DA, Tarjan E \& McKinley MJ (1988). Localization of angiotensin II receptor binding in rabbit brain by in vitro autoradiography. J ournal of Comparative Neurology, 270: 372-384.

5. Williams J L, Barnes $\mathrm{KL}$, Brosnihan $\mathrm{KB} \&$ Ferrario CM (1992). Area postrema - A unique regulator of cardiovascular function. News in Physiological Sciences, 7:
30-34

6. Bishop VS \& Sanderford MG (2000). Angiotensin II modulation of the arterial baroreflex: role of the area postrema. Clinical and Experimental Pharmacology and Physiology, 27: 428-431.

7. Head GA (1996). Role of AT1 receptors in the central control of sympathetic vasomotor function. Clinical and Experimental Pharmacology and Physiology, 23: 593S98.

8. Averill DB \& Diz DI (2000). Angiotensin 
peptides and baroreflex control of sympathetic outflow: Pathways and mechanisms of the medulla oblongata. Brain Research Bulletin, 51: 119-128.

9. Bickerton RK \& Buckley JP (1961). Evidence for a central mechanism in angiotensin induced hypertension. Proceedings of the Society for Experimental Biology and Medicine, 106: 834-836.

10. Severs WB, Daniels AE, Smookler $\mathrm{HH}_{\text {, }}$ Kinnard WJ \& Buckley JP (1966). Interrelationship between angiotensin II and the sympathetic nervous system. J ournal of Pharmacology and Experimental Therapeutics, 153: 530-537.

11. Hoffman WE \& Phillips MI (1976). Regional study of cerebral ventricle sensitive sites to angiotensin II. Brain Research, 110: 313-330.

12. Head GA \& Williams NS (1992). Hemodynamic effects of central angiotensin I, II and III in conscious rabbits. American J ournal of Physiology, 263: R845-R851.

13. Wright JW, Sullivan MJ, Petersen EP \& Harding J W (1985). Brain angiotensin II and III binding and dipsogenicity in the rabbit. Brain Research, 358: 376-379.

14. Tarjan E, Denton DA, McBurnie MI \& Weisinger RS (1988). Water and sodium intake of wild and New Zealand rabbits following angiotensin. Peptides, 9: 677679.

15. Head GA, Elghozi J -L \& Korner PI (1988). Baroreflex modulation of central angiotensin II pressor responses in conscious rabbits. J ournal of Hypertension, 6 (Suppl 6): S505-S507.

16. Elghozi J -L \& Head GA (1990). Spinal noradrenergic pathways and the pressor responses to central angiotensin II. American J ournal of Physiology, 258: H240$\mathrm{H} 246$.

17. Bendle RD, Malpas SC \& Head GA (1997). Role of endogenous angiotensin II on sympathetic reflexes in conscious rabbits. American J ournal of Physiology, 272: R1816-R1825.

18. Keim KL \& Sigg EB (1971). Activation of central sympathetic neurons by angiotensin II. Life Sciences, 10: 565-574.

19. Keil LC, Summy-Long J \& Severs WB (1975). Release of vasopressin by angiotensin II. Endocrinology, 96: 1063-1065.

20. Steele MK, Gardner DG, Xie PL \& Schultz HD (1991). Interactions between ANP and ANG II in regulating blood pressure and sympathetic outflow. American J ournal of Physiology, 260: R1145-R1151.

21. Tobey J C, Fry HK, Mizejewski CS, Fink GD \& Weaver LC (1983). Differential sympathetic responses initiated by angio- tensin and sodium chloride. American J ournal of Physiology, 245: R60-R68.

22. Barron KW, Trapani AJ, Gordon FJ \& Brody MJ (1989). Baroreceptor denervation profoundly enhances cardiovascular responses to central angiotensin II. American J ournal of Physiology, 257: H314H323.

23. Head GA (1994). Cardiac baroreflexes and hypertension. Clinical and Experimental Pharmacology and Physiology, 21: 791802.

24. Head GA (1995). Baroreflexes and cardiovascular regulation in hypertension. J ournal of Cardiovascular Pharmacology, 26 (Suppl 2): S7-S16.

25. Dorward PK \& Rudd CD (1991). Influence of the brain renin-angiotensin system on renal sympathetic and cardiac baroreflexes in conscious rabbits. American J ournal of Physiology, 260: H770-H778.

26. Saigusa T \& Head GA (1993). Renal sympathetic baroreflex effects of angiotensin II infusions into the rostral ventrolateral medulla of the rabbit. Clinical and Experimental Pharmacology and Physiology, 20: 351-354.

27. Mayorov DN \& Head GA (2001). Influence of rostral ventrolateral medulla on renal sympathetic baroreflex in conscious rabbits. American J ournal of Physiology, 280: R577-R587.

28. Reid IA \& Chou L (1990). Analysis of the action of angiotensin II on the baroreflex control of heart rate in conscious rabbits. Endocrinology, 126: 2749-2756.

29. Chapleau MW, Hajduczok G \& Abboud FM (1989). Peripheral and central mechanisms of baroreflex resetting. Clinical and Experimental Pharmacology and Physiology, 15: 31-43.

30. Okuno T, Nagahama S, Lindheimer MD \& Oparil S (1983). Attenuation of the development of spontaneous hypertension in rats by chronic central administration of captopril. Hypertension, 5: 653-662.

31. Gaudet E, Godwin SJ \& Head GA (2000). Effects of central infusion of angiotensin II and losartan on baroreflex control of heart rate in rabbits. American J ournal of Physiology, 278: H558-H566.

32. Gaudet E, Godwin SJ \& Head GA (1998). Role of central catecholaminergic pathways in the actions of endogenous ANG II on sympathetic reflexes. American J ournal of Physiology, 275: R1174-R1184.

33. Liu J L, Murakami $H$, Sanderford $M$, Bishop VS \& Zucker IH (1999). ANG II and baroreflex function in rabbits with CHF and lesions of the area postrema. American J ournal of Physiology, 277: H342-
H350.

34. Bartholomeusz B \& Widdop RE (1995). Effect of acute and chronic treatment with the angiotensin II subtype 1 receptor antagonist EXP 3174 on baroreflex function in conscious spontaneously hypertensive rats. J ournal of Hypertension, 13: 219225.

35. Zucker IH, Wang W, Pliquett RU, Liu J L \& Patel KP (2001). The regulation of sympathetic outflow in heart failure. The roles of angiotensin II, nitric oxide, and exercise training. Annals of the New York Academy of Sciences, 940: 431-443.

36. Hirooka Y, Head GA, Potts PD, Godwin SJ , Bendle RD \& Dampney RAL (1996). Medullary neurons activated by angiotensin II in the conscious rabbit. Hypertension, 27: 287-296.

37. Speth RC, Wamsley JK, Gehlert DR, Chernicky CL, Barnes KL \& Ferrario CM (1985). Angiotensin II receptor localization in the canine CNS. Brain Research, 326: 137-143.

38. Benarroch EE, Granata AR, Ruggiero DA, Park DH \& Reis DJ (1986). Neurons of C1 area mediate cardiovascular responses initiated from ventral medullary surface. American J ournal of Physiology, 250: R932-R945.

39. Allen AM, Dampney RAL \& Mendelsohn FAO (1988). Angiotensin receptor binding and pressor effects in cat subretrofacial nucleus. American J ournal of Physiology, 255: H1011-H1017.

40. Andreatta SH, Averill DB, Santos RA \& Ferrario CM (1988). The ventrolateral medulla. A new site of action of the reninangiotensin system. Hypertension, 11: I163-I-166.

41. Sasaki S \& Dampney RAL (1990). Tonic cardiovascular effects of angiotensin II in the ventrolateral medulla. Hypertension, 15: 274-283.

42. Chan RKW, Chan YS \& Wong TM (1991). Responses of cardiovascular neurons in the rostral ventrolateral medulla of the normotensive Wistar Kyoto and spontaneously hypertensive rats to iontophoretic application of angiotensin-II. Brain Research, 556: 145-150.

43. Li YW \& Guyenet PG (1996). Angiotensin II decreases a resting $\mathrm{K}^{+}$conductance in rat bulbospinal neurons of the $\mathrm{Cl}$ area. Circulation Research, 78: 274-282.

44. Chemow B, Alexander HR, Smallridge RC, Thompson WR, Cook D, Beardsley D, Fink MP, Lake CR \& Fletcher J R (1987). Hormonal responses to graded surgical stress. Archives of Internal Medicine, 147: 1273-1278. 
45. Hirooka Y, Potts PD \& Dampney RAL (1997). Role of angiotensin II receptor subtypes in mediating the sympathoexcitatory effects of exogenous and endogenous angiotensin peptides in the rostral ventrolateral medulla of the rabbit. Brain Research, 772: 107-114.

46. Potts PD, Allen AM, Horiuchi J \& Dampney RAL (2000). Does angiotensin II have a significant tonic action on cardiovascular neurons in the rostral and caudal VLM. American J ournal of Physiology, 279: R1392-R1402.

47. Fontes MAP, Baltatu O, Caligiorne SM, Campagnole-Santos MJ , Ganten D, Bader M \& Santos RAS (2000). Angiotensin peptides acting at rostral ventrolateral medulla contribute to hypertension of TGR (MREN2)27 rats. Physiological Genomics, 2: 137-142.

48. Chalmers J \& Pilowsky P (1991). Brainstem and bulbospinal neurotransmitter systems in the control of blood pressure. J ournal of Hypertension, 9: 675-694.

49. Li YW, Gieroba Z], McAllen RM \& Blessing WW (1991). Neurons in rabbit caudal ventrolateral medulla inhibit bulbospinal barosensitive neurons in rostral medulla. American J ournal of Physiology, 261: R44R51.
50. Allen AM, Mendelsohn FAO, Gieroba Z) \& Blessing WW (1990). Vasopressin release following microinjection of angiotensin-II into the caudal ventrolateral medulla oblongata in the anaesthetized rabbit. J ournal of Neuroendocrinology, 2: 867-873.

51. Saigusa $T$, Iriki $M \&$ Arita J (1996). Brain angiotensin II tonically modulates sympathetic baroreflex in rabbit ventrolateral medulla. American J ournal of Physiology, 271: H1015-H1021.

52. Berger AJ (1979). Distribution of carotid sinus nerve afferent fibers to solitary tract nuclei of the cat using transganglionic transport of horseradish peroxidase. Neuroscience Letters, 14: 153-158.

53. Allen AM, Chai SY, Clevers J, McKinley MJ , Paxinos G \& Mendelsohn FAO (1988). Localization and characterization of angiotensin II receptor binding and angiotensin converting enzyme in the human medulla oblongata. J ournal of Comparative Neurology, 269: 249-264.

54. Paton J F \& Kasparov S (2000). Sensory channel specific modulation in the nucleus of the solitary tract. J ournal of the Autonomic Nervous System, 80: 117-129.

55. Casto R \& Phillips MI (1984). Cardiovascular actions of microinjections of angioten- sin II in the brain stem of rats. American J ournal of Physiology, 246: R811-R816.

56. Diz DI, Barnes KL \& Ferrario CM (1984). Hypotensive actions of microinjections of angiotensin II into the dorsal motor nucleus of the vagus. J ournal of Hypertension, 2: 53-56.

57. Casto R \& Phillips MI (1986). Angiotensin II attenuates baroreflexes at nucleus tractus solitarius of rats. American J ournal of Physiology, 250: R193-R198.

58. Paton J FR \& Kasparov S (1999). Differential effects of angiotensin II on cardiorespiratory reflexes mediated by nucleus tractus solitarii: a microinjection study in the rat. J ournal of Physiology, 521: 213225.

59. Campagnole-Santos M J , Diz DI \& Ferrario CM (1988). Baroreceptor reflex modulation by angiotensin II at the nucleus tractus solitarii. Hypertension, 11: I-167-I-171.

60. Kasparov S, Butcher JW \& Paton JFR (1998). Angiotensin II receptors within the nucleus of the solitary tract mediate the developmental attenuation of the baroreceptor vagal reflex in pre-weaned rats. J ournal of the Autonomic Nervous System, 74: 160-168. 